\title{
Aspects of Arbitration Discourse: an Insight into China's Arbitration Law
}

\author{
Maurizio Gotti \\ Università degli Studi di Bergamo \\ maurizio.gotti@unibg.it
}

\begin{abstract}
The formulation of legal norms is greatly conditioned not only by different juridical systems and drafting traditions, but also by specific linguistic features and socio-cultural aspects. The paper investigates this issue by taking into consideration provisions concerning commercial arbitration in an Asian country. The text selected for our analysis is The People's Republic of China Arbitration Law 1994 (PRCAL, for short). This law can be considered a highly important step in the development of Chinese legislation in this field as it has had a great impact on international arbitration carried out by Chinese companies.

International business exchanges with China have increased enormously over the last few years and even the recent economic recession has not slowed down this growth, making China the biggest Asian market in terms of import-export trade. As a natural consequence, this increase in business deals and contracts has brought about a rise in the number of trade disputes, with a consequent increase in arbitration proceedings.

The aim of this paper is to examine the English version of PRCAL in order to highlight some of the linguistic and legal features present that betray specific cultural values. In some cases, the PRCAL text is compared to the United Nations Model Law on International Commercial Arbitration, with the aim of offering a more detailed understanding of textual phenomena closely linked to differing legal and cultural traditions.
\end{abstract}

Keywords: arbitration discourse, China, cultural constraints, legislative drafting, conciliation 


\section{Cultural constraints on legislative drafting}

It is a well-known fact that the formulation of legal norms has been found to be greatly conditioned not only by different juridical systems and drafting traditions, but also by specific linguistic features and socio-cultural aspects. Juridical systems may influence legal discourse significantly, as can be seen in the differentiation between civil law and common law texts: the former are mainly characterised by generality, while the latter prefer particularity. Indeed, it is commonly asserted that civil law statutes are written in terms of principle, whereas common law statutes are written in detail, as "the civil code draftsman is eager to be widely understood by the ordinary readership, whereas the common law draftsman seems to be more worried about not being misunderstood by the specialist community" (Bhatia, 1993; 137). This stylistic difference derives from a basic conceptual differentiation underlying the two legal systems: in the civil law system the judiciary is entrusted with the task of applying the general principles outlined in the civil code to specific real-life situations and, as such, privileges stylistic choices such as generality and simplicity of expression. The common law system, instead, is based on the principle of precedence, by means of which the decisions taken by one judge become binding on all subsequent similar cases and consequently regards certainty of expression as the most valued quality in legal drafting.

This conceptual differentiation is reflected in the drafters' stylistic choices: in common law legislation sentences are very long, consisting of three or more main clauses, each modified by many subordinate clauses; this remarkable sentence length depends on the great number of details to be inserted and the need that specifications should be precise and clear (Tiersma, 1999). Civil law sentences are shorter, with a more flexible use of paragraphing which makes the understanding of the sentences easier, but renders the reconstruction of the relationship between the various sentences more complex. The adversarial nature of the common law system is probably also a factor, causing drafters to address ever more remote contingencies (Hill / King, 2004). Indeed, common law legislation is usually associated with particular emphasis on precision and detail for action in specific circumstances (Campbell, 1996). This explains why laws devote various parts of their text to very detailed terminological explanations and the use of past-participle clauses to state clearly the source of the qualification of a term.

Another reason for divergency in drafting behaviour concerns the degree of exactness or vagueness with which legal drafters phrase their texts, an issue debated in various studies (cf., for example, Endicott, 2000; Bhatia et al., 2005; Poscher, 2012). This divergency depends on the contrasting requirements of an ideal legal text: on the one hand, it needs to be maximally determinate and precise, so that there should be no doubt about what is meant by its words whereas, on the other, it needs to cover every relevant situation, i.e., it has to be all-inclusive. Therefore, if precision and determinacy are achieved through explicitness and absence of vagueness, this process of limiting the possible interpretations of a normative text often leads to the exclusion of aspects that ought to have been covered by it. Indeed, normative texts are meant to be highly impersonal and decontextualised, but at the same time they also deal with the universe 
of human behaviour, which means they have to be very clear, on the one hand, and allinclusive, on the other. As a consequence, the drafters of such texts must be determinate and vague at the same time, depending upon the extent to which they can predict every conceivable contingency that may arise in the application of what they write.

As regards the constraint of specific linguistic and cultural factors in the formulation of normative texts, even a rapid analysis reveals that they perform a very influential role. If we particularly focus on the arbitration field, this is clearly visible in those cases in which the national legislation imposes specific obligations in compliance with local customs and traditions: for example, countries such as Korea and Saudi Arabia uphold requirements of nationality and/or residence for a person to serve as arbitrator (Jarvin, 1999: 60); Saudi Arabia furthermore requires arbitrators to be male and of the Islamic faith (Saleh, 1992: 549). These criteria impose serious restrictions on the choice of arbitration in an international dispute and are usually taken into consideration by foreigners when they have to decide on the site of an arbitration case with a party residing in one of those countries. But even when cultural differences are not so obviously manifest, it is impossible to guarantee a perfectly homogeneous process, as the various legal patterns of the countries involved will re-emerge in some of the procedures described or in a few of the principles set out. Such professional traits will not only characterise the written texts, but will also be present in the minds of the arbitrators themselves, who - no matter how neutral and culturally open they wish to be - will inevitably be conditioned by their own specific legal philosophy. This emergence of the arbitrator's educational and professional background may create problems in the assessment of the parties' behaviour and originate negative consequences on the outcome of the proceedings themselves, a risk international arbitrators are fully aware of:

[A]n arbitrator, without relinquishing the most impartial frame of mind, may nonetheless remain very distant, in educational and cultural terms, from the particular party or its counsel. In such a case, difficulties are likely to arise which have nothing to do with the probity of the arbitrator in question. They are due solely to the fact that said arbitrator reveals a greater intellectual propensity to grasp every detail of the arguments put forward by one party, while encountering objective and honest difficulties in understanding the submissions of the other(s) in the same way. Albeit unwillingly, the conduct of the arbitrator may thus adversely affect the equal treatment of the parties. (Bernini, 1998: 42)

Particularly in those cases in which arbitrators are professional judges, they may be influenced by the different role that such a figure plays in common law and civil law proceedings (cf. David / Brierley, 1985). They are so deeply involved in their own system that they tend to follow the same procedures they are used to adopting in their habitual environment. With the common law 'adversarial' approach, the judge has a more passive role as the final decision is normally taken by a jury rather than the judge himself. In the civil law 'inquisitorial' procedure, instead, judges play a more active role in the conduct of the proceedings as they are not only permitted but expected to take greater initiative in the assessment and evaluation of facts (cf. Borris, 1994, 1999). 
This differentiation in the judge's role also derives from the way in which the gathering of evidence is carried out in the two legal systems. In civil law procedure, the parties are required to state their case with all necessary detail and to present all documents and evidence relied on as early as possible. Common law procedure, on the other hand, is typically oriented towards the oral hearing, with greater importance attributed to witness examination; all details of the case deemed relevant by the parties must be pleaded at the oral hearing even if such pleadings have already been made in the written statements. This derives from the fact that the jury is not involved in the proceedings prior to the oral hearing, but decides the facts of the case solely on the evidence presented at the trial. Therefore, in common law procedure the judge generally leaves the examination of witnesses to the parties or their counsel and does not, on his own initiative, encourage the parties to settle the case. In contrast, civil law judges usually examine witnesses themselves and are more likely to encourage the parties to settle the case.

Another differentiation between common law and civil law practices consists in the possibility for a party to give evidence as a witness; this is acceptable in common law jurisdictions, while in civil law tradition this is not generally the case, as it is considered unlikely that a party will give a testimony which may differ from the papers that they have previously submitted. The less formal situation of the arbitration case, however, enables the arbitrator to call a party to make any statement that may be in support of their own case. This testimony is made less binding also by the absence of putting the witnessing party under oath. A similar difference exists as regards written testimony; this is not accepted as evidence in civil law procedure, while it is in common law systems. In international arbitration - where the parties involved are often located in distant countries - written witness statements are admitted. However, in this case too, the arbitrator's cultural background will influence his attitude towards these statements: common law arbitrators will tend to give credence to signed testimony, particularly if it is sworn; civil law arbitrators, on the other hand, will be more cautious in the acceptance of a signed document, as they assume that it was prepared by someone other than the signatory, namely, his lawyers.

Interesting cultural differentiations may emerge also as regards the preparation of witnesses and experts with a view to their participation in hearings before the arbitral tribunal; these too may reflect profound ethical differences between the parties in conflict. In some countries it is considered the normal practice to prepare them for this process (including trial performances recorded on video), a procedure which may be considered shocking and even reproachable from the ethical and professional perspective of jurists from a different cultural background. For example, it is generally considered contrary to Italian professional ethical rules for lawyers to discuss a case in detail with a witness in private prior to calling him to give evidence and a legal representative who breaches this ethical code may expose himself to a complaint to the law society and to disciplinary action (Cavasola / Paton, 1994).

As has been seen, the formulation of legal norms is greatly conditioned by sociocultural constraints. It is the purpose of this paper to investigate this issue by analysing 
the provisions concerning commercial arbitration in an Asian country. The text selected for our analysis is The People's Republic of China Arbitration Law 1994 (PRCAL, for short). ${ }^{1}$ This law can be considered a very important step in the development of Chinese legislation in this field as it has had a great impact on international arbitration carried out by Chinese companies. The aim of this paper is to examine the English version of PRCAL in order to highlight some of the salient linguistic and legal features that betray specific cultural values. In some cases, the text of PRCAL will be compared to the UNCITRAL Model Law on International Commercial Arbitration (ML for short), ${ }^{2}$ with a view to offering a more detailed understanding of textual phenomena closely linked to differing legal and cultural traditions.

\section{Topical and definitional aspects}

The coverage of PRCAL and that of ML does not always correspond in terms of topical content, as the organisation of content reflects the different contexts in which they are embedded: most PRCAL provisions also apply to domestic commercial arbitration with only Chapter VII dealing specifically with international awards. On the other hand, ML approaches the matter more systematically, with no allowance for domestic cases. ML opens with a definition of legal scope, status and interpretation (Chapter I) and then follows a chronological progression from the drafting of a commercial contract to the eventual recourse against the award (particularly in Chapters III-VI). However, in PRCAL further articles have been inserted, where emphasis is given to other aspects, such as reference to local arbitration commissions or special provisions for arbitration involving foreign elements. The amount of legal mapping clearly depends on the different origins of these two texts as well as their purpose.

Moreover, PRCAL gives hardly any terminological definitions, whereas ML devotes several articles to this purpose: for example, Art. 2 provides the definition of the basic concepts of this field, such as 'arbitration', 'arbitral tribunal' and 'court', while Art. 7 clearly specifies the concept of 'arbitration agreement'. This is in line with the common law drafting tradition, which places great emphasis on the precise and detailed wording of the text in order to limit any possibility of ambiguity or misunderstanding (Driedger, 1982). PRCAL, instead, gives hardly any terminological definitions which is also, to some extent, due to the fact that the monocultural background of PRCAL is in fact less likely to require such specifications. Moreover, the Chinese text displays a high degree of intertextual linking as this new law is embedded in the extant body of legislation, and therefore has to be interpreted in the light of several other texts of greater or equal authority, whereas ML is a stand-alone law.

This more precise way of drafting the text is also visible in the choice of the ML drafter to give a title to every article of the Model Law in order to facilitate the comprehension of each specific provision. Such headings are, inversely, missing in the Chinese text. The greater detail in wording the text results in longer formulations of the provisions. Indeed, although the Chinese text has more articles (80 vs 36), the ML 
document contains more words $(7,207$ vs 4,659). In terms of word count, this means that each article in ML is longer and more structured, with a higher number of words per article.

\section{References to the local socio-cultural system}

The text of PRCAL at times contains terms that seem to have a specific meaning which reflects in particular the Chinese political or legal system or betrays a local cultural aspect. A clear reference to the Chinese political system is traceable in the opening lines of the law, where one of its main goals is identified as the development of the socialist market economy:

(1) This Law is formulated in order to ensure the impartial and prompt arbitration of economic disputes, to protect the legitimate rights and interests of the parties and to safeguard the sound development of the socialist market economy. (PRCAL Art. 1)

Another case in which local cultural aspects can be detected is in the provisions regarding the selection of arbitrators. In the arbitration process, arbitrators play a very active role and enjoy a great degree of autonomy due to the fact that no jury is involved in the proceedings and that the majority of the disputes are of a technical and complicated nature. Moreover, arbitrators often make proposals for an amicable settlement of the dispute if they see any feasible solutions. It is important, therefore, that the decision-making process should be totally transparent and that the arbitrator should be impartial and independent. This need is particularly felt in the Chinese context, where arbitration has often been regarded as too sensitive to the local parties' interests and pressures as affirmed by Professor Jerome Cohen from New York University, quoted by Jane Moir in an article in the South China Morning Post (5 October 2001):

The longer my experience as either an advocate or an arbitrator in disputes presented to CIETAC [China International Economic and Trade Arbitration Commission], the graver my doubts have become about its independence and impartiality. [...] At a minimum, I would surely no longer advise clients to accept CIETAC jurisdiction unless the contract's arbitration clause required the appointment of a third country national as presiding arbitrator (cited in Bhatia / Candlin / Wei 2001: 8).

The situation does not seem to have improved in the last few years and general international opinion about Chinese local arbitration institutions seems to be very skeptical as illustrated by the following remarks about the behaviour of the Hangzhou Arbitration Commission in the proceedings over the dispute between the Chinese Wahaha Group and the French Groupe Danone:

Why the hell would you agree to arbitration in Hangzhou, the home base of your very strong JV [joint venture] partner? Come on, did you have absolutely no leverage in the 
negotiation process or did someone screw this one up? (Abrams, 2007, quoted in Corona, 2011: 137)

Zong filed for arbitration, too, with the Hangzhou Arbitration Commission, the kangaroo court in his hometown. [...] Expecting an independent hearing from the Hangzhou Arbitration Commission is like expecting an honest report about Tiananmen Square from the People's Daily newspaper. It just isn't going to happen. (Levant, 2007, quoted in Corona, 2011: 137)

These considerations provide an explanation for the specific norms that the Chinese arbitration law has laid down to regulate the challenge of appointed arbitrators. In particular, these norms contain specific reference to such important issues as the arbitrator's competence, impartiality and independence:

(2) In one of the following circumstances, the arbitrator must withdraw, and the parties shall also have the right to challenge the arbitrator for a withdrawal:

(1) The arbitrator is a party in the case or a close relative of a party or of an agent in the case;

(2) The arbitrator has a personal interest in the case;

(3) The arbitrator has other relationship with a party or his agent in the case which may affect the impartiality of arbitration; or

(4) The arbitrator has privately met with a party or agent or accepted an invitation to entertainment or gift from a party or agent. (PRCAL Art. 34)

In ML, instead, this issue is considered in very general terms:

(3) $[\ldots]$ The court or other authority, in appointing an arbitrator, shall have due regard to any qualifications required of the arbitrator by the agreement of the parties and to such considerations as are likely to secure the appointment of an independent and impartial arbitrator and, in the case of a sole or third arbitrator, shall take into account as well the advisability of appointing an arbitrator of a nationality other than those of the parties. (ML 11.5)

It is evident that the choice of arbitrators is of immense importance: they must be figures of sufficient professional standing to satisfy the parties of their competence in resolving the issue(s) and add personal credibility to the legal validity of the procedure. As a consequence, the PRCAL drafters have decided to provide detailed specifications as regards the qualifications of an arbitrator, thus clearly mentioning specific reasons for challengeability in those cases in which an arbitrator has privately met with a party or agent or accepted an invitation to entertainment or a gift from them, which might imply the arbitrator's embezzlement of funds, acceptance of bribes or involvement in malpractice for personal benefits. 


\section{Terms with a specific local meaning}

The analysis of the PRCAL text has highlighted the use of some terms which have a specific local meaning. Indeed, the formulation of particular legal norms relies on typical cultural implications involved in dispute resolution in the Chinese legal system. This shows that the cultural environment has greatly influenced the outcome of the drafting process.

\subsection{Arbitration commission}

Some of the terms contained in the text of PRCAL have given rise to disputes as regards their true interpretation as they seem to have a specific local meaning, one of which can be found in art. 10 of PRCAL:

(4) Arbitration commissions may be established in municipalities directly under the Central Government and in cities that are the seats of the people's governments of provinces or autonomous regions. They may also be established in other cities divided into districts, according to need. Arbitration commissions shall not be established at each level of the administrative divisions. (PRCAL Art. 10)

The term arbitration commission is not commonly used in documents relative to international arbitration, where the term arbitral institution is usually employed. Although the common interpretation is to consider these two terms as synonymous, in practice they are not, because elsewhere arbitral institutions are independent institutions, while in China they are seen as closely linked with the complex system of local and national government and cannot therefore be established in an autonomous way. This close link with local and national government can be pernicious to a fair and independent resolution of the dispute, as Glück and Lichtenstein aptly observe:

While the legislation requires a strict legal separation between the administrative authorities and these domestic arbitral institutions, it should be noted that, in reality, these legal safeguards are not always effective. Not all domestic arbitral institutions are free from judicial and administrative interference. Local protectionism and political influence are common problems. (2014: page)

Other scholars have expressed much stronger criticism towards the close links between arbitral tribunals and local government, such as, for example, Moser and Yuen's opinion about the degree of independence of the arbitration tribunal of CIETAC (China International Economic and Trade Arbitration Commission):

Foreign parties have frequently voiced concerns about the independence and impartiality of CIETAC tribunals. Despite specific provisions in the Arbitration Law and the 2000 Rules aimed at ensuring impartiality, the fact remains that many Chinese members of the CIETAC Panel of Arbitrators are either current or retired government officials and 
CIETAC itself, while officially independent, enjoys close ties to government departments. (2005: 396)

Further problems concerning the term arbitration commission derive from its usage in Article 16 of PRCAL, which reads:

(5) $[\ldots]$ An arbitration agreement shall contain the following particulars:

(1) an expression of intention to apply for arbitration;

(2) matters for arbitration; and

(3) a designated arbitration commission. (PRCAL Art. 16)

The failure to designate a specific arbitration commission in the arbitration agreement has led to the invalidity of the agreement itself and therefore to the impossibility of carrying out such procedure. This has also occurred in cases of an imprecise formulation of the commission's name or due to its vague reference as local arbitral institution or a similar expression.

Another question raised by the use of the indeterminate term arbitration commission is whether such an expression only refers to Chinese arbitration institutions or also encompasses foreign arbitration institutions. Although the arbitration commission referred to in Article 16 of PRCAL could also be interpreted in a broad sense so as to cover any arbitration body wherever it is domiciled (Chang 2001), it is commonly assumed that only local arbitration commissions may be indicated in the arbitration agreement. This interpretation also guarantees a safer recognition of the final award, as aptly pointed out by Tao and Von Wunschheim:

[...] even when an arbitration clause expressly refers to the foreign arbitration institution, it is uncertain whether such an arbitration clause would be regarded as valid in China considering the controversy as to the interpretation of the term 'arbitration commission'. This will not prevent a foreign arbitration institution from handling a Chinese arbitration case, but it may endanger the enforceability of the resulting award. (2007: 324)

This helps to explain the fact that there are no foreign arbitration institutions operating in China and that it is still rare for a foreign arbitration institution to deal with an arbitration proceeding taking place in China. On the other hand, there is a continuous growth in the number of local arbitration institutions being set up.

\subsection{Foreign-related arbitration}

Another expression which has proved ambiguous in interpretative terms is foreignrelated arbitration. This term appears in several provisions mainly grouped in Section 7 of PRCAL dealing with "special provisions for arbitration involving foreign elements". The first article in this section defines international arbitration in very vague terms: 
(6) The provisions of this Chapter shall apply to the arbitration of disputes arising from economic, trade, transportation and maritime activities involving a foreign element. (PRCAL Art. 65)

The following article deals with the organization of foreign-related arbitration commissions, but does so in an indeterminate way, which is clearly shown by the use of may (instead of shall) in two of the three sentences of the provision:

(7) Foreign-related arbitration commissions may be organized and established by the China Chamber of International Commerce. A foreign-related arbitration commission shall be composed of one chairman, a certain number of vice chairmen and members. The chairman, vice chairmen and members of a foreign-related arbitration commission may be appointed by the China Chamber of International Commerce. (PRCAL Art. 66, emphasis added)

The deliberate use of may is intended to give greater decisional powers to the China Chamber of International Commerce, again an institution closely linked with the local government. Also, the analysis of the use of modal verbs in the PRCAL text carried out by Bhatia and Candlin leads them to conclude that "[a]lthough not stated explicitly, it is clear [...] that executive bodies are assigned more power than the parties in the arbitration process" (2008: 135). The powers of the China Chamber of International Commerce in this matter are also clearly strengthened by a subsequent article of the law, which reads:

(8) Foreign-related arbitration rules may be formulated by the China Chamber of International Commerce in accordance with this Law and the relevant provisions of the Civil Procedure Law. (PRCAL Art. 73)

In this way the law does not explicitly confer exclusive jurisdiction over foreignrelated cases to foreign-related arbitration commissions, but rather implies that jurisdiction is meant to be concurrent with local arbitration commissions. Indeed, it has often been pointed out (e.g. Zhou, 2006) that the law would have used shall instead of may if it had intended to reserve jurisdiction on foreign-related cases exclusively to foreign arbitration commissions.

However, the fact that foreign-related cases are dealt with in a specific section of the law seems to imply that international arbitration cases may be seen as separate from the domestic ones. Indeed, it has been noted that international arbitration cases are commonly dealt with somewhat differently: judicial review of international arbitration is mainly focused on procedural issues, while review of domestic arbitration concentrates on more substantive aspects (Yifei, 2012).

The choice of foreign-related rather than non-domestic or international - two adjectives commonly found in documents concerning international commercial arbitration - seems to imply the willingness to guarantee complete autonomy to the Chinese adjudicating system, without any necessary application of criteria followed 
elsewhere. Also the use of the expression foreign-related arbitration award found in this law is intended to provide greater autonomy of decision on the part of Chinese institutions as this term is so indeterminate as to be applicable not only to foreignrelated arbitration cases carried out in China, but also to those proceedings conducted in a foreign country and which would, thus, be ruled by the New York Convention. However, since China did not sign a reciprocity agreement within that convention, the Chinese legislators did not want to run the risk of any automatic recognition of an award issued in a foreign country.

When PRCAL came into force, the expression foreign-related arbitration award was used also for awards deriving from arbitration proceedings held in Hong Kong since at that time this area was still a British colony. When the Hong Kong territory was handed over to the People's Republic of China as a Special Administrative Region, an agreement on mutual recognition and enforcement of arbitral awards between Hong Kong and Mainland China was signed and became effective on February 1, 2000. This agreement permits the High Court of Hong Kong to enforce Mainland Chinese awards made pursuant to the Arbitration Law of the People's Republic of China, and the Intermediate People's Court in China to enforce awards made in Hong Kong. Under this agreement, awards from either place are to be considered domestic, and no longer to be examined according to the New York Convention.

\subsection{Public interest}

Another element which strengthens the autonomy of the Chinese legal system and its great power over the arbitration decision is the interesting concept of 'public interest', explicitly mentioned in PRCAL in Article 58:

(9) If the people's court determines that the arbitration award violates the public interest, it shall rule to set aside the award. (PRCAL Art. 58)

Although this concept is not explicitly mentioned in Section 7 of PRCAL as a reason for challenging or invalidating a foreign-related award, this possibility is implicitly evoked in an indirect way. Indeed, Article 71 states:

(10) If the party against whom the enforcement is sought presents evidence which proves that the foreign-related arbitration award involves one of the circumstances set forth in the first paragraph of Article 260 of the Civil Procedure Law, the people's court shall, after examination and verification by a collegial panel formed by the people's court, rule to disallow the enforcement. (PRCAL Art. 71)

If one analyses the circumstances set forth in the first paragraph of Article 260 of the Civil Procedure Law, one finds that this provision states that Chinese courts may deny the recognition and enforcement of foreign-related arbitral awards according to the 'public interest' criterion. This concept is, of course, quite vague and thus enables local courts to act more autonomously. The use of this term has aroused intense criticism as it 
is found only in the Chinese context and is thus more liable to be employed and interpreted in an idiosyncratic way. In traditional international law, instead, the term commonly used is public policy, a term which has been amply discussed and clarified in specialised literature all over the world (e.g. Lew / Mistelis / Kröll, 2003). For example, in publications concerning the interpretation of this term as used in the New York Convention, public policy is usually conceived of as narrowly limited to the violation of a state's international public policy or international public order (Zhou, 2006: 448). The meaning of public interest, instead, seems to be wider than that of public policy and seems to go beyond notions of morality and justice, to include general financial, cultural, environmental and other interests, as Zhou aptly remarks:

Technically, any enforcement may have a substantial impact on the financial situation of an interest group, and the public interest defense may therefore be abused as a ground for defending arbitral awards. This wide-open ground offered a convenient channel for local protectionists in China. (Zhou, 2006: 448)

\section{Vagueness}

As we have seen, the text of PRCAL presents several cases of vague and indeterminate formulations. Apart from the reasons pointed out in the specific cases dealt with above, a further explanation may be provided by the fact that the vagueness of the English translation examined here may derive from the typical traits of Chinese legal language. Indeed, Chinese legal language has been found vaguer and more ambiguous than other traditions, such as, for example, English legal language (Ross \& Ross, 2000). Peerenboom (2002), for instance, claims that Chinese legislation is characterised by generality and vagueness, with frequent cases of undefined terms and inconsistent usage. Keller (1994) attributes this greater vagueness and indeterminacy to the particular need for generality and flexibility that is at the basis of legislative drafting in that country. This higher degree of flexibility derives from the need to guarantee the unitary nature of the state while preserving respect for regional diversity. This also favours greater legislative stability, since it allows broader generality of application by means of varying interpretations of the law rather than actual changes to existing legislation. This is also due to the fact that specific meanings attached to many legislative terms shift with their contexts, a trait that has always characterised Chinese legal language based on Confucian tradition. According to Potter (2001) this traditional indefiniteness of legal terms is also due to the preference of Chinese administrative bodies for broadly drafted laws that may grant them greater freedom in their application in specific contexts. A more general explanation may be found in the fact that China has a civil law tradition, which generally favours broader and more general legal drafting compared to that of common law countries.

To exemplify the indefiniteness of Chinese legal language, Cao (2008) mentions the case of the frequent use of the word deng (meaning etc., such as, including) in Chinese legal texts and adds: 
The habitual and sometimes over-frequent use of deng which allows for open-ended interpretations can cause a great deal of uncertainty and ambiguity. A further problem is that deng can indicate both open-endedness when listing things and can also be used to end a listing, a closure, to be all inclusive, depending on actual use and context. (2008: 112)

Indeed, several cases of open-endedness have been found in the English translation of PRCAL, deriving from the use of deng in the original text, as the examples below show (emphasis added):

(11) An arbitrator shall meet one of the conditions set forth below: [...] To have acquired the knowledge of law, engaged in the professional work in the field of economy and trade, etc., possessing a senior professional title or having an equivalent professional level. (PRCAL Art. 13)

(12) A foreign-related arbitration commission may appoint arbitrators from among foreigners with special knowledge in the fields of law, economy and trade, science and technology, etc. (PRCAL Art. 67)

Moreover, the text often includes 'weasel words' (Mellinkoff 1963: 21), i.e. words and expressions which have flexible meanings, such as serious, equitable, justified, reasonable:

(13) In arbitration, disputes shall be resolved on the basis of facts, in compliance with the law and in an equitable and reasonable manner. (PRCAL Art. 7)

(14) If an arbitrator is involved in the circumstances described in item (4) of Article 34 of this Law and the circumstances are serious or involved in the circumstances described in item (6) of Article 58 of this Law, he shall assume legal liability according to law and the arbitration commission shall remove his name from the register of arbitrators. (PRCAL Art. 38)

(15) The arbitration commission shall notify the parties of the date of the hearing within the time limit specified in the rules of arbitration. A party may, within the time limit specified in the rules of arbitration, request a postponement of the hearing if he has justified reasons therefore. The arbitration tribunal shall decide whether or not to postpone the hearing, (PRCAL Art. 41)

Also, the issues that can be subjected to arbitration are not specified in a clear way. The matter is dealt with in Article 3:

(16) The following disputes may not be arbitrated:

(1) marital, adoption, guardianship, support and succession disputes;

(2) administrative disputes that shall be handled by administrative organs as prescribed by law. (PRCAL Art. 3) 
As can be seen, while the issues concerning civil cases are listed in subclause 1, the ones concerning 'administrative disputes' are stated vaguely and are even more indeterminately referred to as law in general. This indeterminacy has led to the challenging of arbitration awards due to the claim that the matter was not arbitrable. One such case was the dispute over product quality defect between a hospital in Zhouzhou City and Mr Ding reviewed in Yifei (2012). The hospital did not accept the arbitration award of the Zhouzhou Arbitration Commission (which was unfavourable to them), and applied to the Zhouzhou Intermediate Court to cancel it, arguing that the Arbitration Commission did not have the right to accept disputes involving product quality defects, as this matter concerned medical malpractice, and was therefore to be considered an administrative dispute.

\section{The use of conciliation in arbitration}

Alternative dispute resolution is mainly divided into two main forms: arbitration, on the one hand, and conciliation/mediation, on the other. While in arbitration the procedure results in an arbitration award, which is as binding as the decision of a judge of first instance, in conciliation/mediation, agreement is reached by the parties through the work of a neutral party, who helps them analyze the true interests involved in the dispute and leads them towards a resolution of the dispute, without imposing any decision (Berger, 2006). In theory, mediation and conciliation should have their own fields of application deriving from the specific characteristics of these two instruments, the techniques and the tactics they employ, and the professional preparation of the experts working in each field. In practice, the terms 'mediation' and 'conciliation' are often used as synonyms for the same concept, that is, an informal cooperation towards the solution of a controversy thanks to the neutral participation of a third party.

In Western legal culture the dispute resolution field is clearly divided into three well distinguished areas: litigation, arbitration and conciliation/mediation with no possibilities of mixing the two procedures. In the Asian context instead, conciliation often combines and interferes with the other two legal procedures, i.e. litigation and arbitration. This is due to the fact that conciliation has a long tradition there, and for centuries it has been considered the best way of solving disputes. In the past, a good judge was not supposed to give a judgment but to try to bring about a good conciliation. Indeed, for the Chinese, litigation is seen as a harmful way of dispute resolution as it may result in loss of face and friendship. Although China established a judicial system very early in its history, the Chinese emphasis on morality encouraged individuals or groups in conflict to resolve their differences by means of discussion or compromise rather than adjudication. The traditional Chinese preference for mediation and conciliation over formal methods of dispute resolution has its origins in Confucian philosophy, which views social conflicts as a shameful aberration of morality and as a form of disruption of the natural order of social life. Instead, conciliation and compromise are considered virtues to be used in conflict resolution. Even the radical political and economic changes which have taken place in China in the past seventy 
years have not completely affected this culture and a strong emphasis on conciliation has been maintained. The judge's primary obligation is said to be not to decide cases but to educate the parties so as to induce them to terminate their dispute (Liao, 2012).

This explains why one of the main features of the Chinese legal system is the integration between conciliation and arbitration. This concept of hybrid dispute processing is also present in Japanese legal culture (Sato, 2008) which is due, as said before, to the fact that the tradition of using conciliation to settle disputes in Asia dates back to the ancient past. Conciliation is a preferred means of settling disputes whenever possible, but it is neither a necessary nor compulsory step in the arbitration proceeding. If conciliation is successful, a settlement agreement will be reached and the case will be closed by the disputing parties. If, instead, a settlement agreement cannot be reached within a reasonable period of time, the proceeding will continue according to the arbitration procedure. This double possibility is clearly stated by Article 51 of PRCAL:

(17) The arbitration tribunal may carry out conciliation prior to giving an arbitration award. The arbitration tribunal shall conduct conciliation if both parties voluntarily seek conciliation. If conciliation is unsuccessful, an arbitration award shall be made promptly.

If conciliation leads to a settlement agreement, the arbitration tribunal shall make a written conciliation statement or make an arbitration award in accordance with the result of the settlement agreement. A written conciliation statement and an arbitration award shall have equal legal effect. (PRCAL Art. 51)

As can be seen, there is no clear indication of an exact procedure to be followed in passing from conciliation to arbitration. Article 51 only specifies that conciliation should take place "prior to giving an arbitration award". Usually, after the first phase in which the facts of the case are established, the parties realize how well grounded or not their claims are and therefore become aware of the real possibilities of winning the case. If they think that they are not absolutely sure of achieving a successful result, they may be more than willing to conciliate the case. Referring to a specific case, Trappe (2003) gives a clear description of how such a double procedure can take place:

In the case under review, the conciliators explained to the parties the material aspects of the case [...] in a hearing at which all parties and their representatives attended. In that hearing, they invited each of the parties to move away from its original standpoint, i.e. respectively to decrease its claim or to offer a certain amount of money. They patiently [...] again and again called on each party to make a step forward towards their opponent. Once a stand-off was reached, they adjourned the hearing for a short while and invited the parties to meet alone with the party-appointed conciliator and, later, with the conciliator the other party had appointed. Such separate meetings (unthinkable in arbitration proceedings) were held repeatedly. In these separate meetings, the conciliators tried to convince the respective party that its standpoint, either damaging or defending, did not appear to be justified or realistic. Thus, the proceedings went step by step until the approach of both parties was so close to each other that a meeting of minds occurred and a separate agreement was signed. In the instant case, this stage was reached in the very late evening of the third day, just a short 
while before the last plane suitable for the charterer left, so that one of the conciliators wrote down the agreement in manuscript. (2003: 379)

This double possibility combined within the same procedure has been criticized particularly by scholars mainly living in Western countries. Others, instead, with a deeper knowledge of Eastern arbitral practices are less critical, a divergence Moser and Yuen point out:

Many have argued that it is not appropriate for a single person or a tribunal to wear the hats of both conciliator and arbitrator, the point here being that an arbitrator who fails to settle a dispute by conciliation and resumes the arbitration will run the grave risk of infringing the principles of natural justice. However, many have also argued the contrary: provided that certain safeguards are put in place during the conciliation process, the two procedures can work side-by-side. (2005: 401)

\section{Conclusion}

As can be seen from the analysis carried out so far, legislative drafting is a complex task which is greatly conditioned by different factors relating to the specific cultural, linguistic and legal environments in which it takes place. The discussion of certain linguistic and textual features of PRCAL has provided interesting insights into how the drafting of this document has been influenced by specific legal cultures and standardised professional procedures, and has demonstrated that - in comparison with ML - variations in formulation are to be attributed mainly to the different cultural traits and legal traditions of the communities for which they are intended. This comparison has shown that, in spite of the fact that the two texts are similar in terms of topical content and coverage, they suggest interesting divergences in terms of clarity of expression and conceptual and terminological precision, which may also depend on the common law tradition reflected in the UN document and the civil law perspective adopted by Chinese legislators, the former favouring precision and detailed guidelines for action in specific circumstances, the latter taking a more systematic approach, with arbitration firmly embedded within the country's highly codified domestic legislation.

As the analysis presented here has shown, PRCAL often reveals instances of vagueness. The presence of vague textual formulations is due to several reasons, the main one being that normative texts aim to be as all-inclusive as possible in order to be valid in the widest range of applications. Moreover, in many cases the text is worded in a vague way so as to guarantee the maximal use of the discretionary powers of the judging authority to decide what is appropriate or inappropriate. However, the consideration that legislation on arbitration in the People's Republic of China is not always precise and unambiguous has given rise to the fear outside the PRC that the system does not always guarantee equal opportunities and fair treatment to non-Chinese parties. 
Furthermore, the analysis of the specificity of information included in the two texts studied here has shown that they may differ significantly due to variations in sociocultural expectations and practices that constrain social behaviour in local contexts. A relevant case in point was seen in the comparison of the article concerning the grounds for challenging the appointment of arbitrators: the UNCITRAL text is expressed in more general terms, while in the Chinese arbitration law the constraints are described in greater detail. This substantiates our initial claim that the phenomenon of legal drafting is greatly influenced by the linguistic aspects and legal traditions of the local community to which the drafters belong and to which the provision is addressed. As language is inseparable from set cultural implications and is deeply involved in social norms, linguistic and cultural constraints are bound to arise in the complex process of formulation of legal norms.

\section{Notes}

1. PRCAL was promulgated by the Standing Committee of the National People's Congress of the PRC on 31 August 1994 and came into force on 1 September 1995. Although the original text was written in Standard Chinese, also known as Mandarin and Putonghua, here we will be examining its English version, available at $<$ http://www.wipo.int/wipolex/en/text.jsp?file_id=182634>.

2. The UNCITRAL Model Law (United Nations document A/40/17, Annex I) was adopted on 21 June 1985 by the Commission on International Trade Law (UNCITRAL) and is available online at <http://www.uncitral.org/uncitral/en/uncitral_texts/arbitration/ 1985Model_arbitration.html.

\section{References}

Abrams, Stan (2007): "Danone v. Wahaha: No sympathy". At $<$ http://www.chinahearsay.com/danone-wahaha-no-sympathy/>.

Bernini, Giorgio (1998): "Is there a growing international arbitration culture?". In ICCA (International Council for Commercial Arbitration), International Dispute Resolution: Towards an International Arbitration Culture. Albert Jan van den Berg (Gen. ed.). Dordrecht: Kluwer Law International, 41-46.

Bhatia, Vijay K. (1993): Analysing Genre: Language Use in Professional Settings. London: Longman.

Bhatia, Vijay K. and Christopher Candlin (2008): "Interpretation across legal systems and cultures: a critical perspective". In Bhatia, Candlin and Engberg (eds.), 127-144

Bhatia, Vijay K., Christopher Candlin and Sandy Wei (2001): Legal Discourse in Multilingual and Multicultural Contexts: A Preliminary Study. Research Group Report. Hong Kong: City University of Hong Kong.

Bhatia, Vijay K., Christopher Candlin, and Jan Engberg (eds.) (2008): Legal Discourse across Cultures and Systems. Hong Kong: Hong Kong University Press.

Bhatia, Vijay K., Jan Engberg, Maurizio Gotti and Dorothee Heller (eds.) (2005): Vagueness in Normative Texts. Bern: Peter Lang. 
Borris, Christian (1994): "Common Law and Civil Law: fundamental differences and their impact on arbitration". Arbitration 60(2): 78-85.

Borris, Christian (1999): "The Reconciliation of conflicts between Common Law and Civil Law principles in the arbitration process". In Frommel and Rider (eds.), 1-18.

Cao, Deborah (2008): "Is the Chinese legal language more ambiguous and vaguer?". In Anne Wagner and Sophie Cacciaguidi-Fahi (eds.), Obscurity and Clarity in the Law: Prospects and Challenges. Aldershot: Ashgate, 109-125.

Campbell, Lisbeth (1996): "Drafting styles: fuzzy or fussy?" ELaw. Murdoch University Electronic Journal of Law 3(2). Available at $<$ http://www.murdoch.edu.au/elaw/issues/v3n2/campbell.html >.

Cavasola, Pietro and Andrew G. Paton (1994): "Italy". In Eijsvoogel, Peter V. (ed.), Evidence in International Arbitration Proceedings. London: Graham \& Trotman, 165-174.

Chang, Wang Sheng (2001): "Formation of the arbitral tribunal". Arbitration International 17(1): 401-410.

Corona, Isabel (2011): “Arbitration recontextualized”. World Englishes 30(1): 129-140.

David, Rene and John E. Brierley $\left({ }^{3} 1985\right)$ : Major Legal Systems in the World Today. An Introduction to the Study of Comparative Law. London: Stevens and Sons.

Driedger, Elmer A. (1982): "Legislative drafting style: Civil Law versus Common Law". In Jean-Claude Gémar (ed.), Langage du droit et traduction / The Language of the Law and Translation. Montreal: Linguatech / Conseil de la Langue Française, 63- 81.

Endicott, Timothy (2000): Vagueness in Law. Oxford: Oxford University Press.

Frommel, Stefan N. and Barry A.K. Rider (eds.) (1999): Conflicting Legal Cultures in Commercial Arbitration: Old Issues and New Trends. The Hague: Kluwer Law International.

Glück, Ulrike and Falk Lichtenstein (2014): Arbitration in the People's Republic of China. CMS Guide to Arbitration, Vol I. at $<\mathrm{http} / / /$ eguides.cmslegal.com/pdf/arbitration_volume_I/CMS\%20GtA_Vol\%20I_CHINA.pd f>.

Hill, Clare and Christopher King (2004): "How do German contracts do as much with fewer words?". Chicago-Kent Law Review 79: 889-926.

Jarvin, Sigvard (1999): "Leading arbitration seats: a (mostly European) comparative view". In Frommel and Rider (eds.), 39-61.

Keller, Perry (1994): "Sources of order in Chinese law". The American Journal of Comparative Law 42(4), 711-759.

Levant, Ezra (2007): “Danone vs. Wahaha". At <http://ezralevant.com/2009/08/danonevswahaha.html>.

Lew, Julian, Loukas Mistelis and Stefan Kröll (2003): Comparative International Commercial Arbitration. The Hague: Kluwer Law International.

Liao, Meizhen (2012): "Courtroom discourse in China”. In Tiersma and Solan (eds.), 395-407.

Mellinkoff, David (1963): The Language of the Law. Boston: Little, Brown \& Co.

Moser, Michael and Peter Yuen (2005): "The New CIETAC Arbitration Rules". Arbitration International 21(3): 391-403.

Peerenboom, Randall (2002): China's Long March toward Rule of Law. Cambridge: Cambridge University Press.

Poscher, Ralf (2012): “Ambiguity and vagueness in legal interpretation". In Tiersma and Solan (eds.), 128-144. 
Potter, Pitman B. (2001): The Chinese Legal System: Globalisation and Local Legal Culture. London: Routledge.

Ross, Claudia and Lester Ross (2000): "Language and law: sources of systemic vagueness and ambiguous authority in Chinese statutory language". In Karen Turner, James V. Feinerman and R. Kent Guy (eds.), The Limits of the Rule of Law in China. Washington: The University of Washington Press, 221-270.

Saleh, Samir (1992): "La perception de l'arbitrage au Machrek et dans les pays du Golfe". Revue de l'Arbitrage 4: 549.

Sato, Yasubobu (2008): "Hybrid dispute processing in Japan: linking arbitration with conciliation". In Bhatia, Candlin and Engberg (eds.), 53-74.

Tao, Jingzhou and Clarisse Von Wunschheim (2007): "Articles 16 and 18 of the PRC Arbitration Law: the Great Wall of China for foreign arbitration institutions". Arbitration International 23(2): 309-325.

Tiersma, Peter (1999): Legal Language. Chicago: The University of Chicago Press.

Tiersma, Peter and Lawrence Solan (eds.) (2012): The Oxford Handbook of Language and Law. Oxford: Oxford University Press.

Trappe, Johannes (2003): "Beijing-Hamburg conciliation". Arbitration International 19(3): 371-386.

Yifei, Lin (2012): "Judicial review of arbitration agreements in China". Arbitration International 28(2): 243- 293.

Zhou, Jian (2006): "Judicial intervention in international arbitration: a comparative study of the scope of the New York Convention in U.S. and Chinese courts". Pacific Rim Law \& Policy Journal 15(2): 403-455. 